\title{
Dynamics of Social Networks and Collective Behavior: A Social Identity Approach
}

\author{
Amrutha N. Venu ${ }^{\dagger}$, Suman Sigroha ${ }^{1 \dagger}$ and Shail Shankar ${ }^{2 * t}$ \\ ${ }^{1}$ School of Humanities and Social Sciences, Indian Institute of Technology Mandi, Mandi, India, ${ }^{2}$ Department of Humanistic \\ Studies, Indian Institute of Technology Banaras Hindu University, Varanasi, India
}

Keywords: COVID-19, social networks, social relationships, social identity approach, collective behaivor

\section{INTRODUCTION}

As the world grapples with the pandemic, a look at the response of different countries and communities reveals that communities and governance have played a crucial role. The collective efficacy of the communities has helped in mitigating the effects of COVID-19, and as we enter into succeeding stages of this pandemic, collective efficacy continues to serve as the foundational factor. A wide variety of group processes have occurred; we mention the most relevant ones like, group cohesion, solidarity behavior, governance and leadership, social inequalities, discrimination, compliance, and non-compliance of the people to the newer policies and coping behaviors.

The social identity approach, mainly consisting of two theories: social identity theory and social categorization theory (Tajfel and Turner, 1979; Turner et al., 1987), describes collective action as a function of the shared identity between the group members. It suggests that individuals have both personal and shared social identities, and these shared social identities are based on self-categorizations and comparisons. It offers a theoretical basis for understanding the relationship between intragroup and intergroup behaviors (Drury and Reicher, 2009, 712). When people recognize themselves as the members of the group, they share goals and visions of the group and act upon it collectively (Cocking, 2017, 115). Identification as community members, and salience of social identity rather than personal identities, leads to mobilization and collective action which is beneficial for all the group members (Tajfel and Turner, 1979, 35). Social networks and relationships are crucial because they provide a sense of belongingness, recognition (Hopkins et al., 2019, 1292), motivate collective action (Rockenbauch and Sakdapolrak, 2017, 2), and are important for the health of the community members (Poortinga, 2006); and are all a result of cognitive functions.

During the current pandemic many restrictions and limitations have been imposed upon people; they have been forced to isolate themselves, and restrict themselves to socializing virtually. Although, human beings are fundamentally social, and while the need for people or groups is extremely important in times of distress and adversity, because the restrictions have been placed by an external authority or imposed from outside, these limitations challenge people who ultimately violate these restrictions. This is where social identity comes into play. When restrictions or instructions are provided at the individual level, people who belong to the minimum risk category might not necessarily comply. That said, if they are convinced that these restrictions are for the welfare of all, including their group members, behavioral changes happen in a better way. In social identity terms, if personal identity dominates the social identity, people might act in terms of individual benefits rather than community welfare. For example, if an individual who is in the low-risk category perceives that the chances of contracting the virus and having serious consequences are less for her, there is less initiative on her part to comply with the imposed restrictions. But when the risk is perceived at the level of her social identity, as a member of the group, she would be obliged to follow the measures for 
the whole group. Hence invoking behavioral changes in terms of social identity helps better in the present situation.

Effective response to pandemic depends on triggering social identity and through collective behavioural change. Policy measures and other regulations are effective only with the compliance of people. If people perceive the crisis in terms of "me", ("It won't happen to me, I can go out without a mask or necessary precautions") the whole community suffers. However, if this thought is about "we", it will instigate moral responsibility of each group member to the other, which results in collective behavioural change. Understanding the root causes of major behavioural violations and working on it to make it right can increase the adherence of people. When asking to keep physical distance or enforcing to stay at home, the authorities miss to see if it is possible or not. If not, by making arrangements and enabling them to it do as a community can increase the social cohesion and trust between people and authorities. Stating clear and transparent reasons for the strategies adopted, setting clear expectations for the people to modify their response, and developing and promoting a sense of collectivism within the community are some of the common factors that have been adopted by the countries that handled the health emergency better. They proved that actions taken by the authorities, and people in response to the COVID-19 crisis have to be communicated clearly to build mutual trust and support.

All of this takes place in the context of a systematic community set up where systems and organizations are in place. The concept of social capital is explained in these circumstances but there is a failure to explain the emergent group formation which exhibits solidarity behavior, and is crucial at the response and recovery stages (Cocking, 2017, 114). In emergencies and disasters, there is group formation of the victims, not necessarily people belonging to the same community, who express solidarity behaviors. These emergent groups formed out of circumstances or common fate are also able to mobilize collective action (Ntontis et al., 2019 , 2). In terms of the social identity approach, these emergent group formations are a function of a social identification formed because of a common fate or a circumstance; identification happens when people perceive similarities over differences.

The social identity model of collective resilience (SIMCR) (Drury, 2012) is grounded in social identity and social categorization theories, and explains the psychological antecedents, and psychological and behavioral consequences. It helps understand perceptions, expectations, motivations, and behaviors of people in emergencies. It details the process of a cognitive transformation of individual identity to collective identity, which leads to a relational transformation in the ways of interacting with each other that finally leads to an effective transformation of collective action (Cocking, 2017, 115). If applied to the situation arising out of COVID-19, when people behave in a responsible manner (wearing masks and maintaining protocols), a cognitive transformation is said to have occurred. More than protecting themselves, they show a concern for others' their well-being. Getting groceries for the neighbors, watching entry and exit points to note visitors, and helping authorities in contact tracing are some of the behaviors exhibited in different communities the world over. Such solidarity behaviors arise from feeling of a shared identity and a social responsibility, and are exhibited in communities with strong social networks and communications. The sense of solidarity arises when there is a shared bond or a shared goal (Sherif, 1958). Sharing a common destiny becomes the base for feeling a sense of community which eventually contributes to the development of solidarity among individuals and societies. During the present crisis, the collective behavior of the people, cohesion within the community, and the social bonding, and its salience creates resilience. An increase in the mortality rates of an affected population makes a disaster or an emergency critical. (Aldrich, 2019, 75) claims that the determinant factors of mortality rates have shown that the intensity of the event, demographic, and local environmental characteristics, political and economic factors along with the capacity of local social networks affect the mortality rate among the disaster-affected communities. Research suggests that the mortality rates were less during certain disastrous events due to the solidarity behaviors of the community members (Aldrich, 2012; Aldrich, 2019; Goyal, 2019).

\section{CONCEPTUAL REFLECTIONS AND MAJOR TAKEAWAYS}

No doubt disasters and emergencies bring destruction to the community, and disruption in the communication channels. At such times, personal communications between people help in rescue and relief activities through the existence or build-up of strong community ties; dense networks and strong communications help in easy transmission of messages, and timely help. Family members, neighborhood groups, relatives (Aldrich, 2019), pitch-in to rescue in the initial stages and are called "Zero responders" (Briones et al., 2019). COVID-19 has compelled people to follow lockdown measures, thus alienating themselves from their social connections, however communities with strong ties have made sure that their group members are adequately provided for. People have connected widely through the digital platforms, organized community kitchens to provide food for the needy, arranged shelters, all examples of resilience behavior, and made possible because of the strong social networks and relationships, and identification within communities. These social identities evoked community spirit and motivated people to mobilize virtually, and provide necessary support to the vulnerable and the needy. The micro-processes of emergency behavior showed how groups emerge, mobilize, and provide important social support in emergencies or disasters; key psychological transformations (cognitive, relational, and affective) that show group behavior have been explained with the help of the social identity approach. On the cognitive level, perception plays an important part, where individual perception of the self is transformed to a collective level, and changes individual values and goals to collective ones. During these transformations, individual identities are put to rest while group identities become salient, thereby transforming behavior. Solidarity and trust in the group members are the 
result of this transformation (Drury, 2012; Drury, 2018). Apart from community actions and cohesiveness, governmental action has had a major role to play in dealing with the current pandemic.

The present pandemic emphasizes the accountability of governance in handling the crisis. When strict late preventive measures such as lockdowns, curfews, quarantines, and social distancing measures were implemented, they tested both the individual moralities and governance abilities. The pandemic highlighted the loopholes in the governance and the necessity of being self-sufficient. The already existing inequalities widened and the vulnerable population became more vulnerable. That said, even with limitations, communities can be hopeful of a better future if there is suitable integration of social capital and governance. The latter can concentrate on the bottom-up approach and enhance resource mobilization and social support with the help of the community members. Being transparent in actions and being accountable for decisions and plans can be the beginning of an effective relationship with the community. Increasing the competence of the community, communicating clear action-oriented information can empower them and make them self-sufficient. Integration of

\section{REFERENCES}

Aldrich, D. P. (2019). Black Wave: How Networks and Governance Shaped Japan's 3/11 Disasters. Chicago and London: University of Chicago Press. doi:10.7208/ chicago/9780226638577.001.0001

Aldrich, D. P. (2012). Social Capital in post Disaster Recovery: Towards a Resilient and Compassionate East Asian community. Economic and Welfare Impacts of Disasters in East Asia and Policy Responses, ERIA Research Project Report 2011-8, Jakarta: ERIA, 157-178.

Briones, F., Vachon, R., and Glantz, M. (2019). Local Responses to Disasters: Recent Lessons from Zero-Order Responders. Dpm 28 (1), 119-125. doi:10. 1108/dpm-05-2018-0151

Cocking, C. (2017). "Collective Resilience and Social Support in the Face of Adversity- Evidence from Social Psychology," in Routledge International Handbook of Resilience. Editor K. Updesh, 111-123.

Drury, J. (2012). "Collective Resilience in Mass Emergencies and Disasters: a Social Identity Model," in The Social Cure: Identity, Health, and Well-Being. Editors J. Jetten, C. Haslam, and S. A. Haslam (Hove, UK: Psychology Press), 195-215.

Drury, J., and Reicher, S. (2009). Collective Psychological Empowerment as a Model of Social Change: Researching Crowds and Power. J. Soc. Issues 65 (4), 707-725. doi:10.1111/j.1540-4560.2009.01622.x

Drury, J. (2018). The Role of Social Identity Processes in Mass Emergency Behaviour: An Integrative Review. Eur. Rev. Soc. Psychol. 29 (1), 38-81. doi:10.1080/10463283.2018.1471948

Goyal, N. (2019). Disaster Governance and Community Resilience: The Law and the Role of SDMAs. Int. J. Disaster Risk Manage. 1(2), 61-75. doi:10.18485/ijdrm.2019.1.2.5

Hopkins, N., Reicher, S., Stevenson, C., Pandey, K., Shankar, S., and Tewari, S. (2019). Social Relations in Crowds: Recognition, Validation and Solidarity. Eur. J. Soc. Psychol. 49 (6), 1283-1297. doi:10.1002/ejsp.2586 community-based organizations and institutions, and nongovernmental institutions with people and the government is the most effective strategy for handling this world-wide crisis. Losing social connections, maintaining physical distance, stigma, and associated discrimination may culminate into hostility, which can turn people's lives upside down. Empowering social networks and connections, and effective governance as catalyst to enhance the resilience mechanisms of the community can be the solution for surviving the present. The recognition of the importance of we over me is the stepping stone of change during this period. A social identity approach to COVID-19 can help reduce political polarizations, discriminations, and prejudices, and create the "we" feeling through invoking a strong social identity by means of an effective identity governance.

\section{AUTHOR CONTRIBUTIONS}

All authors listed have made a substantial, direct, and intellectual contribution to the work and approved it for publication.

Ntontis, E., Drury, J., Amlot, R., Rubin, G. J., and Williams, R. (2019). What Lies beyond Social Capital? the Role of Social Psychology in Building Community Resilience to Climate Change. Traumatology 26 (3), 253. doi: $10.137 / \operatorname{trm} 0000221$

Poortinga, W. (2006). Social Relations or Social Capital? Individual and Community Health Effects of Bonding Social Capital. Soc. Sci. Med. 63, 255-270. doi:10.1016/j.socscimed.2005.11.039

Rockenbauch, T., and Sakdapolrak, P. (2017). Social Networks and the Resilience of Rural Communities in the Global South: a Critical Review and Conceptual Reflections. E\&S 22 (1), 10. doi:10.5751/ES-09009-220110

Sherif, M. (1958). Superordinate Goals in the Reduction of Intergroup Conflict. Am. J. Sociol., 63 (4), 349-356. The University of Chicago Press. doi:10.1086/ 222258

Tajfel, H., and Turner, J. C. (1979). “An Integrative Theory of Intergroup Conflict,” in The Social Psychology of Intergroup Relations. Editors W. G. Austin and S. Worehel, 33-47.

Turner, J., Hogg, M., Oakes, P., Reicher, S. D., and Wetherell, M. (1987). Rediscovering the Social Group. Oxford, UK: Blackwell.

Conflict of Interest: The authors declare that the research was conducted in the absence of any commercial or financial relationships that could be construed as a potential conflict of interest.

Copyright (c) 2021 Venu, Sigroha and Shankar. This is an open-access article distributed under the terms of the Creative Commons Attribution License (CC $B Y)$. The use, distribution or reproduction in other forums is permitted, provided the original author(s) and the copyright owner(s) are credited and that the original publication in this journal is cited, in accordance with accepted academic practice. No use, distribution or reproduction is permitted which does not comply with these terms. 